\title{
Lipid methodology
}

\author{
D. G. CRAMP ${ }^{1}$
}

From the Alexander Simpson Laboratory for Metabolic Research, St Mary's Hospital Medical School, London

Advances in our knowledge of the circulating lipids and lipoproteins have been dependent on developments in analytical methods. In the past decade or so important advances have been made in this field, and some of the techniques now available to the lipid biochemist include analytical ultracentrifugal flotation (Pedersen, 1945; Gofman, Lindgren, Jones, Lyon, and Strisower, 1951); preparative ultracentrifugation with subsequent chemical analysis of fractions (Lindgren, Elliott, and Gofman, 1951; Hillyard, Entenman, Feinberg, and Chaikoff, 1955; Havel, Eder, and Bragdon, 1955; Bragdon, Havel, and Boyle, 1956); complexing and precipitation with polyanions (Burstein and Samaille, 1960; Bernfeld, Donahue, and Berkowitz, 1957); electrophoresis using various media, including paper (Lees and Hatch, 1963), cellulose acetate (Margolis and Langdon, 1966), starch gel (Kunkel and Slater, 1952), polyacrylamide gel (Narayan, Narayan, and Kummerow, 1965), and agar and agarose gel (Scanu, Lewis, and Page, 1958; Uriel, 1964; Noble 1968); immunological techniques including immunoelectrophoresis (Grabar and Burtin, 1964) and immunodiffusion (Mancini, Carbonara, and Heremans, 1965); membrane filtration (Stone and Thorp, 1966). Other physico-chemical methods such as gas-liquid chromatography (Woodford, 1964), nuclear magnetic resonance (Chapman and Morrison, 1966), refractometry (Lindgren and Nichols, 1960), electron microscopy, $x$-ray techniques (Palmer, Schmitt, and Chargaff, 1941), and infrared and circular dichroic spectroscopy (Scanu and Hirz, 1968) have their place in the research laboratory.

However the two techniques most widely used have been ultracentrifugation with chemical analysis of the density-gradient fractions, and the various types of electrophoresis. Indeed it is on the basis of the latter techniques, with ultracentrifugation as the reference method, that the lipoprotein families have been characterized, thus enabling biochemists and clinicians to gain an understanding of their physiological and pathological significance.

In most clinical laboratories, instead of quantita-

${ }^{1}$ Present address: Department of Chemical Pathology, Royal Free Hospital, Grays Inn Road, London WC1X 8LF tive determination of lipoproteins themselves, measurements of the lipid components of the lipoproteins are carried out. In practice this is limited to triglyceride and cholesterol measurements, which are the minimum requirements for the characterization of hyperlipidaemia and for which reliable manual and automated methods are available.

However, satisfactory estimation of cholesterol and triglyceride depends not only on the use of specific and reproducible procedures but also requires care in the collection, transport, and storage of samples. Primary lipid standards must be used together with appropriate serum reference samples. This latter aspect is well discussed in the WHO memorandum entitled 'Classification of hyperlipidaemias and hyperlipoproteinaemias' (1970).

\section{The Sample}

No matter how good the analytical methodology, the diagnostic value of the final result will be in doubt unless a satisfactory sample is available for analysis. Blood is obtained after an overnight fast of about 10 to 14 hours. It is important that there should be no excessive deviation from normal diet for the previous week or so. Standardization of the method and of conditions of blood sampling are also important. The patient should ideally rest on a bed for at least 30 minutes before the sample is taken because of the changes of serum lipids which occur with posture, which may be of the order of 10 to $15 \%$ (Stoker and Wynn, 1966). Venous stasis should be avoided as this can also cause errors due to haemoconcentration (Koerselman, Lewis, and Pilkington, 1961). Turbid, haemolysed, or markedly icteric samples are unacceptable for some methods and necessitate special blanks in others. Although it has been stated that freezing does not affect either cholesterol or triglyceride analysis it is certain that lipoproteins deteriorate with storage. Electrophoresis should, whenever possible, be carried out quickly using a fresh sample; if, however, samples have to be stored they should be collected in EDTA and kept at $4^{\circ} \mathrm{C}$; they should not be deep frozen (see page 32). 
Blood samples for free fatty acids analysis should be centrifuged and the plasma refrigerated immediately after collection, or alternatively the appropriate volume of plasma can be added immediately to the extraction mixture. Broechoven and Parijs (1968) have shown in a brief study that the free fatty acid concentration remains unchanged for 17 days when the plasma is stored at $+4^{\circ} \mathrm{C}$ or at $-20^{\circ} \mathrm{C}$, but at $+20^{\circ} \mathrm{C}$ the free fatty acid concentration increases markedly and is attributed to lipolysis in vitro. These observations have been confirmed in this laboratory (G. Robertson, unpublished).

\section{Estimation of Triglyceride}

Three basic methods are available for the determination of triglyceride, all of which are based upon isolation of the triglyceride from the serum sample followed by the liberation of the glycerol moiety. The isolation of the triglyceride may be carried out either by selective extraction or solvent extraction plus adsorption. Glycerol is liberated either by saponification with potassium or barium hydroxide, or by transesterification with sodium ethoxide or sodium methoxide (Royer and Ko, 1969). The glycerol released is oxidized to formaldehyde by the action of sodium metaperiodate (McFadyen, 1945; Lambert and Neish, 1950). The formaldehyde may then be determined by several colorimetric procedures, the most common of which is by reaction with chromotropic acid. This reaction has been used for both the manual (Van Handel and Zilversmit, 1957; Carlson and Wadström, 1959) and automated (Lofland, 1964) estimation of triglyceride. A fluorimetric procedure for measuring formaldehyde has also been developed, based on the Hantzsch condensation reaction between an amine, a $\beta$-diketone and an aldehyde; formaldehyde reacts with acetylacetone in the presence of ammonia to form 3,5diacetyl-4-dihydrolutidine. This condensation product fluoresces at $530 \mathrm{~nm}$ when excited with light at $405 \mathrm{~nm}$ (Belman, 1963). A semi-automated method based on this reaction was described by Kessler and Lederer (1966) and improved by Cramp and Robertson (1968). In the latter methods, an unsaponified blank is unnecessary, and an analysis rate of 40 samples per hour on phospholipid-free serum extracts is possible. The method is highly sensitive and suitable for estimation of triglycerides in serum and in the lipoprotein fractions; the results correlate well with the manual reference method of Van Handel and Zilversmit (1957).

Glycerol may also be estimated by enzymatic methods based on its reaction with ATP in the presence of glycerol kinase (GK) (EC 2.7.1.30) and

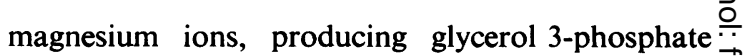
and ADP (Wieland and Suyter, 1957): Glycerol + ATP $\stackrel{\text { GK }}{\rightarrow}$ Glycerol 3-P + ADP. Either of the products of this reaction may be estimated by NAD-dependent auxiliary reactions involving either $\frac{\bar{D}}{\vec{D}}$

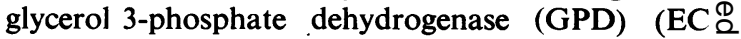
1.1.1.8) or pyruvate kinase (PK) (EC 2.7.1.40), ๗ and lactate dehydrogenase (LD) (EC 1.1.1.27), viz: Glycerol 3-P + NAD $\stackrel{\text { GPD }}{\rightleftharpoons}$ dihydroxyacetone $\overrightarrow{\vec{\omega}}$ phosphate + NADH (Wieland, 1963)

or

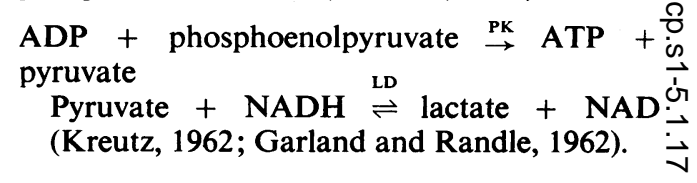

The amount of NAD formed or utilized in these 은 reactions is proportional to the concentration of glycerol present and may be determined by measurement of extinction at 340 or $366 \mathrm{~nm}$ or from the fluorescence produced at $470 \mathrm{~nm}$ after activation at $360 \mathrm{~nm}$. Automated methods have been described $\vec{C}$ by Cramp (1970) and by Bell, Atkinson, and Baron (1970) using enzymatic procedures.

\section{Estimation of Cholesterol}

Although many methods have been described, none is specific enough to be performed directly on plasma; $\stackrel{\mathbb{Q}}{\llcorner}$ preliminary extraction is required either using $a_{\overrightarrow{0}} \overrightarrow{\vec{O}}$ lipoprotein denaturing solvent (isopropanol or 3 chloroform-methanol) or by saponification of the plasma, extracting unsaponifiable material into petroleum ether. Measurement of cholesterol may be photometric, using either acetic anhydride and? acetic acid or ferric chloride to develop colour, or 3 it may be fluorimetric. The highly specific manualmethod of Abell, Levy, Brodie, and Kendall (1952) and that of Anderson and Keys (1956) are recommended as manual reference methods. The auto- mated photometric method of choice is the Tech- $-\frac{D}{8}$ nicon procedure $\mathrm{N} 24 \mathrm{a}$ modified from that of Levine and Zak (1964), with preliminary manual extraction. N

An alternative method is based on the measurement of a stable fluorescent product of the Lieber-O mann-Burchard reaction: the cholesterol extract $\omega$ with trichloroethane, acetic anhydride, and con $\%$ centrated sulphuric acid fluoresces at $590 \mathrm{~nm}$ one excitation at $546 \mathrm{~nm}$. The method was originally described by Albers and Lowry (1955) and modified ${ }^{+}$ by McDougall and Farmer (1957) and Carpenter, $\frac{T}{-}$ Gotsis, and Hegsted (1957). The method of Car- $-\frac{\mathrm{d}}{\mathrm{D}}$ penter et al (1957) was subsequently automated by? Antonis (1964), and this was modified by Robertson and Cramp (1970) who evaluated the method for the 
measurement of cholesterol in serum and in serum lipoprotein fractions. An inherent advantage of the method is the very simple manifold and fairly rapid rate of analysis (60 samples per hour), together with a sensitivity commensurate with that described earlier for triglycerides.

\section{Lipoprotein Fractionation}

Many methods have been described for examining the lipoprotein fractions. Those most widely used are visual inspection of the plasma or serum, electrophoresis, ultracentrifugation and nephelometry. Inspection of the fasting serum sample under standard conditions is important because of its simplicity and relative accuracy in detecting chylomicrons. Electrophoresis is of course cheaper and simpler than ultracentrifugation, but with the latter quantitative values for each lipoprotein fraction can be obtained; ultracentrifugation is therefore the reference method of analysis.

\section{VISUAL INSPECTION}

The fasting serum sample is inspected after it has been allowed to stand overnight at $4^{\circ} \mathrm{C}$. The chylomicrons rise to the surface where they appear as a creamy layer. The turbidity of the underlying serum should also be noted as it reflects the level of verylow-density lipoprotein (VLDL). These two characteristics taken in conjunction with the serum cholesterol and triglyceride levels point to the type of hyperlipoproteinaemia as indicated in the table.

\section{ELECTROPHORESIS}

Any method used for electrophoresis should be capable of sharply defining the four major lipoprotein bands. The media most commonly used are paper, agarose, and cellulose acetate. The relative position of the four bands is much the same on all these media though some chylomicrons are not held at the origin on some cellulose acetate preparations. For paper electrophoresis the method originally described by Lees and Hatch (1963) has given satisfactory results, but has the disadvantage that the $\beta$ - and pre- $\beta$-lipoproteins are only partially separated. A slight disadvantage of cellulose acetate is the lack of reproducible staining. Staining with oil red $\mathrm{O}$ followed by careful differentiation with sodium hypochlorite is recommended (Beckering and Ellefson, 1970). Excellent separation is obtained on agarose gel (Noble, 1968; Hulley, Cook, Wilson, Nichaman, Hatch, and Lindgren, 1971), though cooling is essential, and there may well be important problems in the preparation of the dilute gels. The use of polyacrylamide, either as linear or gradient gel, gives excellent separation but produces a multiplicity of discrete bands, the interpretation of which is not clear. For most laboratories the choice probably lies between cellulose acetate and agarose. It is important to standardize conditions, for the ability to effect discrete separation and to stain reproducibly requires continual surveillance of the apparatus, the current and voltage employed, the regular renewal of buffers and dye, and care with application of the serum at the origin. It must be remembered, however, that some patterns can only be formally identified using ultracentrifugation. With this technique too, standardization of conditions is critical and in particular pycnometry should be employed to standardize the density of the salt solutions used in ultracentrifugation.

\section{NEPHEL OMETR Y}

Nephelometry, in which the measurement of light scattering by the chylomicrons and very low density lipoprotein can be used to estimate triglyceride, is the most important of the other techniques which have been introduced into clinical laboratories (Stone and Thorpe, 1966). It has been claimed that if the plasma is filtered through membranes of different pore sizes the concentration of the chylomicrons and very-low, and possibly of low-density lipoproteins, can be estimated by the light scattering properties of the filtrate. However, the suggestion that low-density lipoproteins can be estimated in this way is based on the erroneous assumption that a constant concentration of high-density lipoprotein is present.

\begin{tabular}{|c|c|c|c|c|}
\hline \multirow[t]{2}{*}{$\begin{array}{l}\text { Type of } \\
\text { Hyperlipoproteinaemia }\end{array}$} & \multirow[t]{2}{*}{$\begin{array}{l}\text { Plasma } \\
\text { Triglyceride }\end{array}$} & \multirow[t]{2}{*}{$\begin{array}{l}\text { Plasma } \\
\text { Cholesterol }\end{array}$} & \multicolumn{2}{|c|}{$\begin{array}{l}\text { Appearance of Fasting Serum after Standing Overnight } \\
\text { at } 4^{\circ} \mathrm{C}\end{array}$} \\
\hline & & & Creamy Top Layer & Turbidity Below \\
\hline $\begin{array}{l}\text { I } \\
\text { II }\end{array}$ & $\begin{array}{l}\text { Increased (chylomicrons) } \\
\text { Normal; may be } \\
\text { slightly increased }\end{array}$ & $\begin{array}{l}\text { Normal; may be increased } \\
\text { Increased }\end{array}$ & + & - \\
\hline $\begin{array}{l}\text { III } \\
\text { IV } \\
\text { V }\end{array}$ & $\begin{array}{l}\text { Increased (VLDL) } \\
\text { Increased (VLDL) } \\
\text { Increased (chylomicrons } \\
\quad+\text { VLDL) }\end{array}$ & $\begin{array}{l}\text { Increased } \\
\text { Normal; may be increased } \\
\text { Increased }\end{array}$ & $\begin{array}{l}\text { Slight } \\
- \\
+\end{array}$ & $\begin{array}{l}+ \\
+ \\
+\end{array}$ \\
\hline
\end{tabular}

Table Diagnostic significance of the appearance of fasting serum after standing overnight at $4^{\circ} \mathrm{C}$ 
The 'SML' profile derived from nephelometric data together with serum total cholesterol has been claimed to provide a simple means of classifying the hyperlipidaemias which is as good as the analytical ultracentrifuge and easier to interpret than the electrophoretic strip (McGill and Scott, 1971). Whilst this view is shared by many (eg, Stone, Thorpe, Mills, and Dick, 1970), others, including ourselves, have reservations about its reliability as a diagnostic procedure, as occasionally it has given high values for triglyceride when direct estimation by the AutoAnalyzer and visual assessment of the pre- $\beta$-lipoprotein band of an electrophoretic strip have both indicated normal values. In such cases, reliance on nephelometric data alone may result in a misclassification of the disorder, eg, type II could be mistaken for type IV. However, nephelometry is the method of choice for the study of fat tolerance using the intravenous fat emulsion, Intralipid (Lewis, Boberg, Mancini, and Carlson, 1972).

Despite the reservations mentioned above, since both analytical and preparative ultracentrifugation are beyond the scope of most routine laboratories, nephelometry does provide a relatively simple alternative which is probably adequate in most cases for diagnosis and control of treatment.

\section{Estimation of Free Fatty Acids}

The titrimetric method of Dole (1956), as modified by numerous investigators, has served as the principal method for determination of free fatty acid concentration. While this method has yielded excellent results it requires considerable skill to perform and is not suitable for the rapid analysis of a large number of specimens. Numerous other methods have been, and still are, being described. The best of these are based on the solubility of copper or cobalt soaps in organic solvents, with subsequent measurement of the optical density of a metal-soap-indicator complex. Duncombe (1963) complexed copper with diethyldithiocarbamate, while Novak (1965) used $\alpha$-nitro- $\beta$-naphthol with cobalt. This latter method is to be recommended for manual use. The method of Duncombe was automated by Antonis (1965) and modified by Dalton and Kowalski (1967) but the difficulties of efficient phase separation of the aqueous copper and chloroform layers can hamper the efficiency of the method.

A good automated method recently published is that of Carruthers (1972) based on the adsorption of the fluorescent indicator fluorescein onto the free fatty acid molecule, with consequent loss of fluorescence. This loss of fluorescence is stoichiometrically related to the concentration of free fatty acids.

Because of the size of the !iterature on methods for lipid and lipoprotein analysis only certain aspects have been discussed, and a comprehensive review has not been attempted. A more extensive discussion will be found in such volumes as those edited by Tria and Scanu (1969) and Nelson and Rouser (1972).

\section{References}

Abell, L. L., Levy, B. B., Brodie, B. B., and Kendall, F. E. (1952). Simplified method for the estimation of total cholesterol in serum and demonstration of its specificity. J. biol. Chem., 195, 357-366.

Albers, R. W., and Lowry, O. H. (1955). Fluorimetric determination of 0.1 to 10 micrograms of cholesterol. Analyt. Chem., 27, $1829-1831$.

Anderson, J. T., and Keys, A. (1956). Cholesterol in serum and lipoprotein fractions, its measurement and stability. Clin. Chem., or 2, 145-159. Antonis, A. (1964). In Automation in Analytical Chemistry. (Technicon $\rightarrow-$
Symposium.) New York.

Antonis, A. (1965). Semiautomated method for the colorimetric determination of plasma free fatty acids. J. Lipid Res., 6, 307-312.

Beckering, R. E., and Ellefson, R. D. (1970). A rapid method for lipoprotein electrophoresis using cellulose acetate as support medium. Amer. J. Clin. Path., 53, 84-88.

Bell, J. L., Atkinson, S. M., and Baron, D. N. (1970). An Auto-Analyzer method for estimating serum glyceride glycerol using a glycerokinase procedure. J. clin. Path., 23, 509-513.

Belman, S. (1963). The fluorimetric determination of formaldehyde. Analyt. chim. Acta, 29, 120-126.

Bernfeld, P., Donahue, V. M., and Berkowitz, M. E. (1957). Interaction of human serum $\beta$-lipoglobulin with polyanions. J. biol. Chem., 226, 51-64.

Bragdon, J. H., Havel, R. J., and Boyle, E. (1956). Human serum lipoproteins. I. Chemical composition of four fractions. J. Lab. clin. Med., 48, 36-42.

Broechoven, C., and Parijs, J. (1968). Effect of storage on plasma (D) non-esterified fatty acid concentration. Clin. chim. Acta, 20, 530.

Burstein, M., and Samaille, J. (1960). Sur un dosage rapide du cholesterol lié aux $\alpha$ - et aux $\beta$-lipoprotéines du serum. Clin. chim. Acta, 5, 609.

Carlson, L. A and Wadström, L. B (1959). Determination of gly cerides in blood serum. Clin. chim. Acta, 4, 197-205.

Carpenter, K. J., Gotsis, A., and Hegsted, D. M. (1957). Estimation $\vec{\Omega}$ of total cholesterol in serum by a micro method. Clin. Chem., 3, 233-238.

Carruthers, M. (1972). In Automation in Analytical Chemistry, edited by L. T. Skeggs. London. In press.

Chapman, D., and Morrison, A. (1966). Physical studies of phospholipids. IV. High resolution nuclear magnetic resonance spectra of phospholipids and related substances. J. biol. Chem., 241, 5044-5052.

Cramp, D. G. (1970). Automated fluorimetric techniques based on NAD and NADP linked enzyme systems in the study of inter- $\frac{D}{0}$ mediary carbohydrate metabolism. Med. Lab. Technol., 27, 359- ․ㅡ. 382.

Cramp, D. G., and Robertson, G. (1968). The fluorimetric assay of $\mathrm{N}$ triglyceride by a semiautomated method. Analyt. Biochem. 25, 246-251.

Dalton, C., and Kowalski, C. (1967). Automated colorimetric deter- N mination of free fatty acids in biologic fluids. Clin. Chem., 13, $\omega$ 744-751.

Dole, V. P. (1956). A relation between non-esterified fatty acids in plasma and the metabolism of glucose. J. clin. Invest., 35. 150-154.

Duncombe, W. G. (1963). The colorimetric micro-determination of long-chain fatty acids. Biochem. J., 88, 7-10.

Garland, P. B., and Randle, P. J. (1962). A rapid enzymatic assay for glycerol. Nature (Lond.), 196, 987-988.

Gofman, J. W. Lindgren, F. T., Jones, H. B., Lyon, T. P., and $\vec{D}$ Strisower, B. (1951). Lipoproteins and atherosclerosis. J. Gerontol., 6, 105-119.

Grabar, P., and Burtin, P. (Editors) (1964). Immuno-Electrophoretic Analysis. Elsevier, Amsterdam. 
Havel, R. J., Eder, H. A., and Bragdon, J. H. (1955). The distribution and chemical composition of ultracentrifugally separated lipoproteins in human serum. J. clin. Invest., 34, 1345-1353.

Hayes, T. L., and Hewitt, J. E. (1951). Visualization of individual lipoprotein macromolecules in the electron microscope. J. appl. Physiol., 11, 425-428.

Hillyard, L. A., Entenman, C., Feinberg, H., and Chaikoff, I. L. (1955). Lipide and protein composition of four fractions accounting for total serum lipoproteins. J. biol. Chem., 214, 79-90.

Hulley, S. B., Cook, S. G., Wilson, W. S., Nickaman, M. Z., Hatch F. T., and Lindgren, F. T. (1971). Quantitation of serum lipoproteins by electrophoresis on agarose gel. J. Lipid Res., 12, 420-433.

Kessler, G., and Lederer, H. (1965). Fluorimetric measurement of triglyceride. In Automation in Analytical Chemistry, edited by L. T. Skeggs, pp. 341-344. New York.

Koerselman, H. B., Lewis, B., and Pilkington, T. R. E. (1961). The effect of venous occlusion on the level of serum cholesterol. $J$. atheroscler. Res., 1, 85-88.

Kreutz, F. H. (1962). Enzymatische Glycerinbestimmung. Klin. Wschr., 40, 362-363.

Kunkel, H. G., and Slater, R. J. (1952). Lipoprotein patterns of serum obtained by zone electrophoresis. J. clin. Invest., 31, 677-684.

Lambert, M., and Neish, A. O. (1950). Rapid method for estimation of glycerol in fermentation solutions. Canad. J. Res., 28B, 83-89.

Lees, R. S., and Hatch, F. T. (1963). Sharper separation of lipoprotein species by paper electrophoresis in albumin-containing buffer. J. Lab. clin. Med., 61, 518-528.

Levine, J. B., and Zak, B. (1964). Automated determination of serum total cholesterol. Clin. chim. Acta, 10, 381-384.

Lewis, B., Boberg, J., Mancini, M., and Carlson, L. A. (1972). Determination of the intravenous fat tolerance test with Intralipid by nephelometry. Atherosclerosis, 15, 83-86.

Lindgren, F. T., Elliott, H. A., and Gofman, J. W. (1951). The ultracentrifugal characterization and isolation of human blood lipids and lipoproteins with applications to the study of atherosclerosis. J. phys. Colloid Chem., 55, 80-93.

Lindgren, F. T., and Nichols, A. V. (1960). In The Plasma Proteins, edited by F. W. Putnam, Vol. 2, pp. 1-58. Academic Press. New York and London.

Lofland, H. B., Jr. (1964). A semiautomated procedure for the determination of triglycerides in serum. Analyt. Biochem., 9 , 393-400. Also see addendum (1965). Analyt. Biochem., 10, 178.

McDougal, D. B., Jr., and Farmer, H. S. (1957). A fluorimetric method for total serum cholesterol. J. Lab. clin. Med., 50, 485-488.

MacFadyen, D. A. (1945). Estimation of formaldehyde in biological mixtures. J. biol. Chem., 158, 107-133.

McGill, A. R., and Scott, J. W. (1971). A simple lipid screening programme based on the Thorp nephelometer. Ann. clin. Biochem., 8, 201-204.

Mancini, G., Carbonara, A. O., and Heremans, J. F. (1965). Immunochemical quantitation of antigens by simple radial immunodiffusion. Immunochemistry, 2, 235-254.

Margolis, S., and Langdon, R. G. (1966). Studies in human serum $\beta_{1}$-lipoprotein. III. Enzymatic modifications. J. biol. Chem., 485-493.

Narayan, K. A., Narayan, S., and Kummerow, F. A. (1965). Disk electrophoresis of human serum lipoproteins. Nature (Lond.), 205, 246-248.

Nelson, G. J. (Editor) (1972). Blood Lipids and Lipoproteins. WileyInterscience, London.

Noble, R. P. (1968). Electrophoretic separation of plasma lipoproteins in agarose gel. J. Lipid Res., 9, 693-700.

Novak, M. (1965). Colorimetric ultramicro method for the determination of free fatty acids. J. Lipid Res., 6, 431-433.

Palmer, K. J., Schmitt, F. O., and Chargaff, E. (1941). X-ray diffraction studies of certain lipide-protein complexes. J. cell. Comp. Physiol., 18, 43-47.

Pedersen, K. O. (1945). Ultracentrifugal Studies in Serum and Serum Fractions, p. 167 et seq. Almquist and Wiksell, Uppsala.

Robertson, G., and Cramp, D. G. (1970). An evaluation of cholesterol determinations in serum and serum lipoprotein fractions by a semi-automated fluorimetric method. J. clin. Path., 23, 243-245.

Royer, M. E., and Ko, H. (1969). A simplified semidutomated assay for plasma triglycerides. Analyt. Biochem., 29, 405-416.

Scanu, A., and Hirz, R. (1968). On the structure of human serum high density lipoprotein: studies by the technique of circular dichroism. Proc. nat. Acad. Sci (Wash.), 59, 890-894.

Scanu, A., Lewis, L. A., and Page, I. H. (1958). Studies in the antigenicity of $\beta$ - and $a_{1}$-lipoproteins of human serum. J. exp. Med., 108, 185-196.

Stoker, D. J., and Wynn, V. (1966). Effect of posture on the plasma cholesterol level. Brit. med. J., 1, 336-338.

Stone, M. C. and Thorp, J. M. (1966). A new technique for the investigation of the low-density lipoproteins in health and disease. Clin. chim. Acta, 14, 812-830.

Stone, M. C., Thorp, J. M., Mills, G. L., and Dick, T. B. S. (1970). Comparison of membrane filtration and nephelometry with analytical ultracentrifugation, for the quantitative analysis of low-density lipoprotein fractions. Clin. chim. Acta, 30, 809828.

Technicon Instrument Co., Methodology Sheet No. 24a. Chauncey, New York.

Tria, E. and Scanu, A. M. (Editors) (1969). Structural and Functional Aspects of Lipoproteins in Living Systems. Academic Press. London and New York.

Uriel, J. (1964). In Immunoelectrophoretic Analysis edited by P. Grabar and B. Burtin, pp. 69-70. Elsevier, Amsterdam.

Van Handel, E., and Zilversmit, D. B. (1957). Micromethod for the direct determination of serum triglycerides. J. Lab. clin. Med., 50, 152-157.

Wieland, O. (1963). In Methods of Enzymatic Analysis, edited by H. U. Bergmeyer, pp. 211-214. Academic Press. New York and London.

Wieland, O., and Suyter, M. (1957). Glycerokinase: Isolierung und Eigenschaften des Enzyms. Biochem. Z., 329, 320-331.

World Health Organization Memorandum (1970). Classification of Hyperlipidaemias and Hyperlipoproteinaemias. By J. L. Beaumont et al. Bull. Wld Hlth Org., 43, 891-915,

Woodford, F. P. (1964). In Fatty Acids, edited by K. S. Markley, 2nd ed., pt 3, p. 2249. Interscience, New York. 